\title{
Mid-crustal electrical conductors and their correlations to seismicity and deformation at Itoigawa-Shizuoka Tectonic Line, Central Japan
}

\author{
Yasuo Ogawa ${ }^{1}$ and Yoshimori Honkura ${ }^{2}$ \\ ${ }^{1}$ Volcanic Fluid Research Center, Tokyo Institute of Technology, Tokyo, Japan \\ ${ }^{2}$ Department of Earth and Planetary Sciences, Tokyo Institute of Technology, Tokyo, Japan
}

(Received June 2, 2004; Revised October 12, 2004; Accepted November 3, 2004)

\begin{abstract}
An active fault segment at the northern Itoigawa-Shizuoka tectonic line (ISTL), Central Japan, which will potentially cause M8-class intraplate earthquake, was imaged by wide-band magnetotellurics. Three parallel profiles across ISTL revealed along-strike variation of the resistivity structure. Three resistivity models commonly showed the thickening conductors in the upper crust to east of ISTL which imply the heavily folded Miocene sediments with maximum thickness of several kilometers. Thus the upper crustal structure seems two-dimensional throughout the segment. We found mid-crustal conductors, top of which correlate well with the cutoff depth of seismicity. The seismicity clusters mainly in the resistive crust that is underlain by the mid-crustal conductors. This implies the local distribution of fluids below the brittle-ductile boundary and suggests that the fluid migration into resistive zone is triggering earthquakes. However, the distribution of these mid-crustal conductors is not consistent with the strike of ISTL, but rather it is better correlated with the negative dilatation anomaly inferred from GPS. This suggests the weakening of the crust by the existence of fluids.
\end{abstract}

Key words: Itoigawa-Shizuoka Tectonic Line, magnetotellurics, deformation, fluids.

\section{Introduction}

Magnetotelluric (MT) method can image resistivity structure of the crust, which is mainly controlled by the existence and connectivity of the fluid in the pore spaces and conductive minerals, rather than by the host rock resistivity itself (e.g. Jones, 1992). Thus the MT method has been successfully used for testing the existence of the damaged zones in the upper crust (Ogawa and Honkura, 1997; Unsworth et al., 1999; Ritter et al., 2003) and for imaging the fluid distribution at the mid-crustal depth (Lemonnier $e t$ al., 1999; Honkura et al., 2000; Ogawa et al., 2001, 2002; Mitsuhata et al., 2001; Kasaya et al., 2002; Wannamaker et al., 2002; Tank et al., 2003, 2004).

Distribution of fluids is important in the framework of the earthquake generation processes (e.g., Sibson et al., 1988; Iio and Kobayashi, 2002; Hobbs et al., 2002; Miller, 2002; Gratier et al., 2002). The brittle-ductile boundary can be imaged mechanically by the cut-off depth of the earthquakes, which is controlled by the geotherm (e.g., Tanaka and Ishikawa, 2002). On the other hand, many magnetotelluric studies have shown that the brittle ductile boundary often corresponds to the top of the mid-crustal conductors (e.g., Ogawa et al., 2001; Mitsuhata et al., 2001) and have suggested that the fluids distribute under the brittle-ductile boundary. The existence of the fluids at the brittle-ductile transition is directly supported by the geological evidences at the exhumed deep crustal sections (Cox, 2002; Fujimoto et al., 2002).

Copy right(c) The Society of Geomagnetism and Earth, Planetary and Space Sciences (SGEPSS); The Seismological Society of Japan; The Volcanological Society of Japan; The Geodetic Society of Japan; The Japanese Society for Planetary Sciences; TERRAPUB.
The importance of the fluids at the mid-crust for the earthquake generation is getting attention. The fault valve model (Sibson et al., 1988) relates the distribution of fluids beneath the brittle ductile-boundary to the earthquake. According to the model, tectonic compression causes the cyclic change of the pore pressure and the fluids below the brittle-ductile transition will be episodically released into the brittle crust at the earthquakes. Iio and Kobayashi (2002) proposed an inland (intraplate) earthquake generation model by emphasizing the localized quasi-stationary slip region at the deep extension of the fault, i.e., at the brittle-ductile boundary. The localization of slip was required by the fact that the Japanese historical inland earthquakes did not trigger the neighboring active fault systems. Localized fluid distribution is then important to get a localized slip zone at the brittle-ductile boundary. Thus the MT imaging of the mid-crustal resistivity distribution becomes important.

As part of the multidisciplinary project "Comprehensive joint research on the modeling of slip process of earthquake source fault and plastic flow below the seismogenic region", we carried out MT soundings across the northern segment of Itoigawa-Shizuoka tectonic line (Fig. 1). In this region, we have one of the most active fault segments in Japan, and the strong crustal deformation as described in the next section. It is therefore a good field for testing the localized deformation model for intraplate (inland) earthquakes. The objective of the MT study is to reveal the distribution of the localized fluids as mid-crust conductors in relation to the intraplate fault system. 


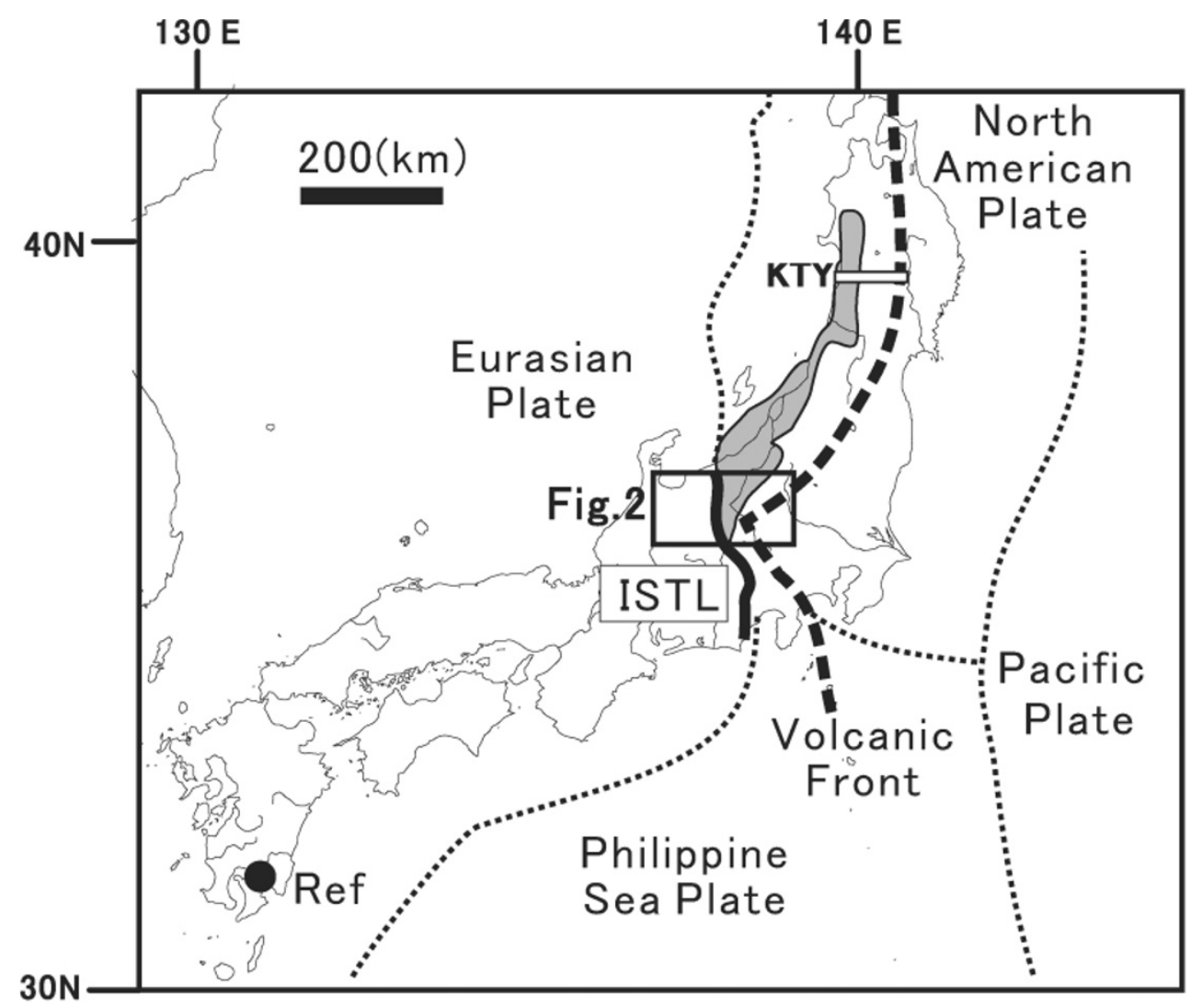

Fig. 1. Location of the study area in the central Japan in the framework of plate configurations. ISTL is shown as a thick line in Central Japan, which is regarded as a boundary between North-American and Eurasian Plates. Ref shows the location of the remote reference site for magnetotelluric measurements. The gray area along the Japan Sea coast is the thick Miocene sedimentary basin created by the Japan Sea opening. KTY is another MT profile by Ogawa et al. (2001).

\section{Geological Setting of the Itoigawa-Shizuoka Tectonic Line}

Our study area is located at the northern segment of Itoigawa-Shizuoka Tectonic Line (ISTL, Fig. 1). ISTL is basically a major geological boundary and a proxy for the plate boundary between the North American Plate and the Eurasian Plate (Nakamura, 1983; Kobayashi, 1983). The pre-Tertiary basement rocks crop out to the west of ISTL (Hida Mountains), whereas to the east the basement is covered with several kilometer thick Miocene sediments. This eastern basin is called "Fossa Magna". As seen in Fig. 1, the thick Miocene sediment distributes along the Japan Sea side from northern part of NE Japan to the study area. This was the center of the rift system, which opened Japan Sea in the Miocene. Thus ISTL was originally created as a normal fault in the rift system, and it was reactivated in the Quaternary as a thrust fault due to the tectonic compression by the Pacific plate subduction. This reactivation is known as a tectonic inversion (Sato and Ikeda, 1999; Sato et al., 2004). The thick sediments in the Fossa magna record the active folding due to the E-W compression. Correspondingly, the triangulation for the last 100 years has detected shortening of up to 30 (ppm/yr) (Sagiya et al., 2002). Current deformation pattern by GPS is also consistent with the geological compression.

Paleo-seismological studies on one of the most active segments of ISTL (Ikeda and Yonekura, 1986; Okumura et al., 1994) revealed unusual large displacement per one earthquake event (8.6-9.5 mm/year) and an unusual short recurrence time (1000 years). Based on these observations, fault system at ISTL is believed to have a potential of M8 earthquake.

Because of the localized active deformation under the Fossa Magna, the northern ISTL provides us with a good field for our hypothesis testing on the genesis of an intraplate earthquake. In particular, our objective is to investigate the distribution of fluids under the deformation zone, which will enable quasi-stationary slip below the brittleductile boundary (Iio and Kobayashi, 2002). We can also compare our results with those from many multidisciplinary studies such as seismic refraction, seismic reflection, and GPS.

\section{Magnetotelluric Measurements}

We carried out magnetotelluric measurements at 68 sites across the northern segment of ISTL (Fig. 2). From the viewpoint of active fault, not all the ISTL is identified as an active fault. In Fig. 2, the bold line denotes the east-dipping active thrust fault segment, "Matsumoto Basin Eastern Boundary Fault". Our wide-band $\left(320 \mathrm{~Hz}-5 \times 10^{-4}\right.$ $\mathrm{Hz}$ ) measurement sites are shown in Fig. 2. During the MT measurements, we used a far-remote reference site in the South Japan to remove the local cultural noise in the study area.

The main profile is a $100 \mathrm{~km}$ long profile, running from Hida Mountains to the Komoro basin. The result of the 


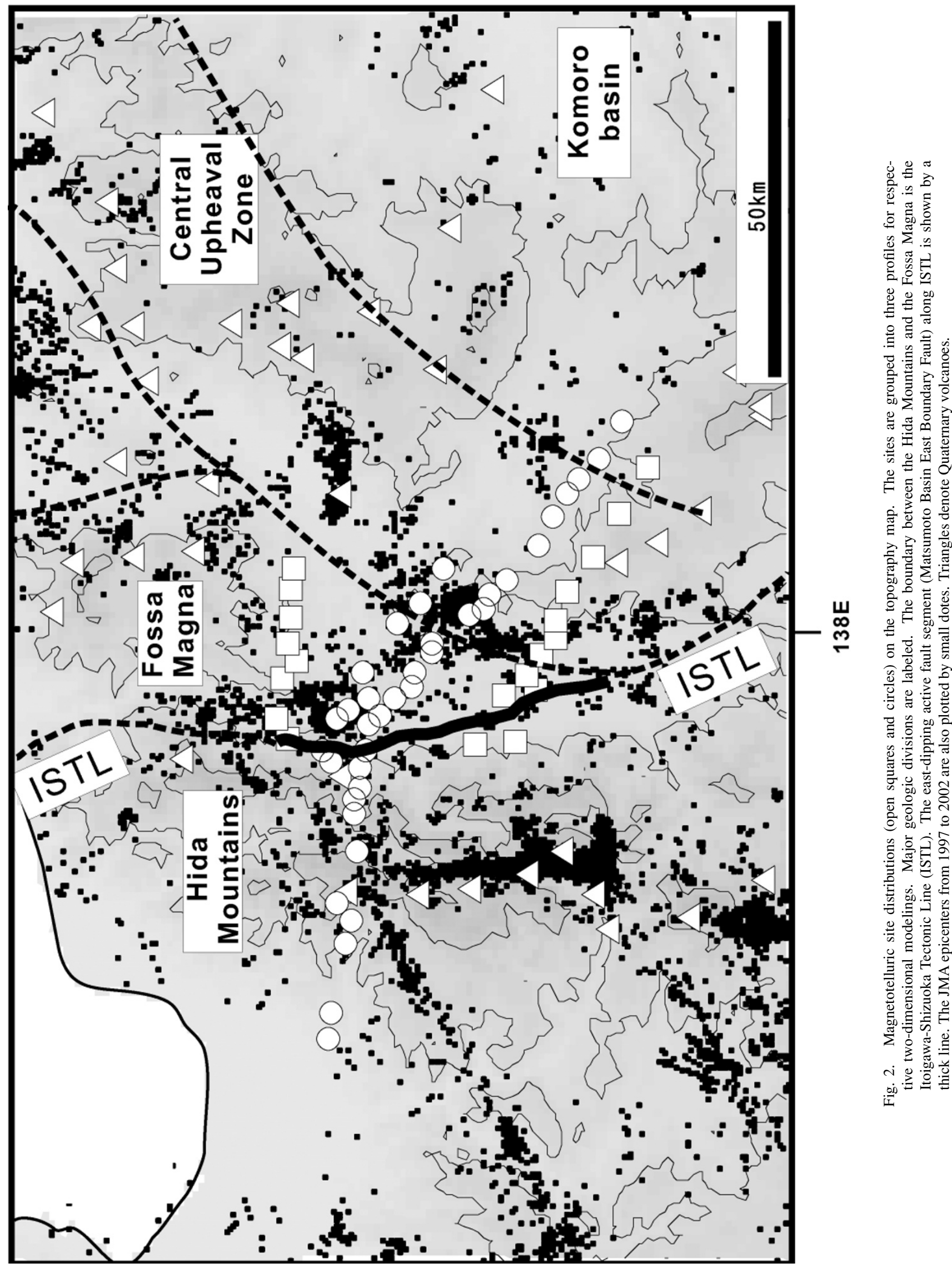




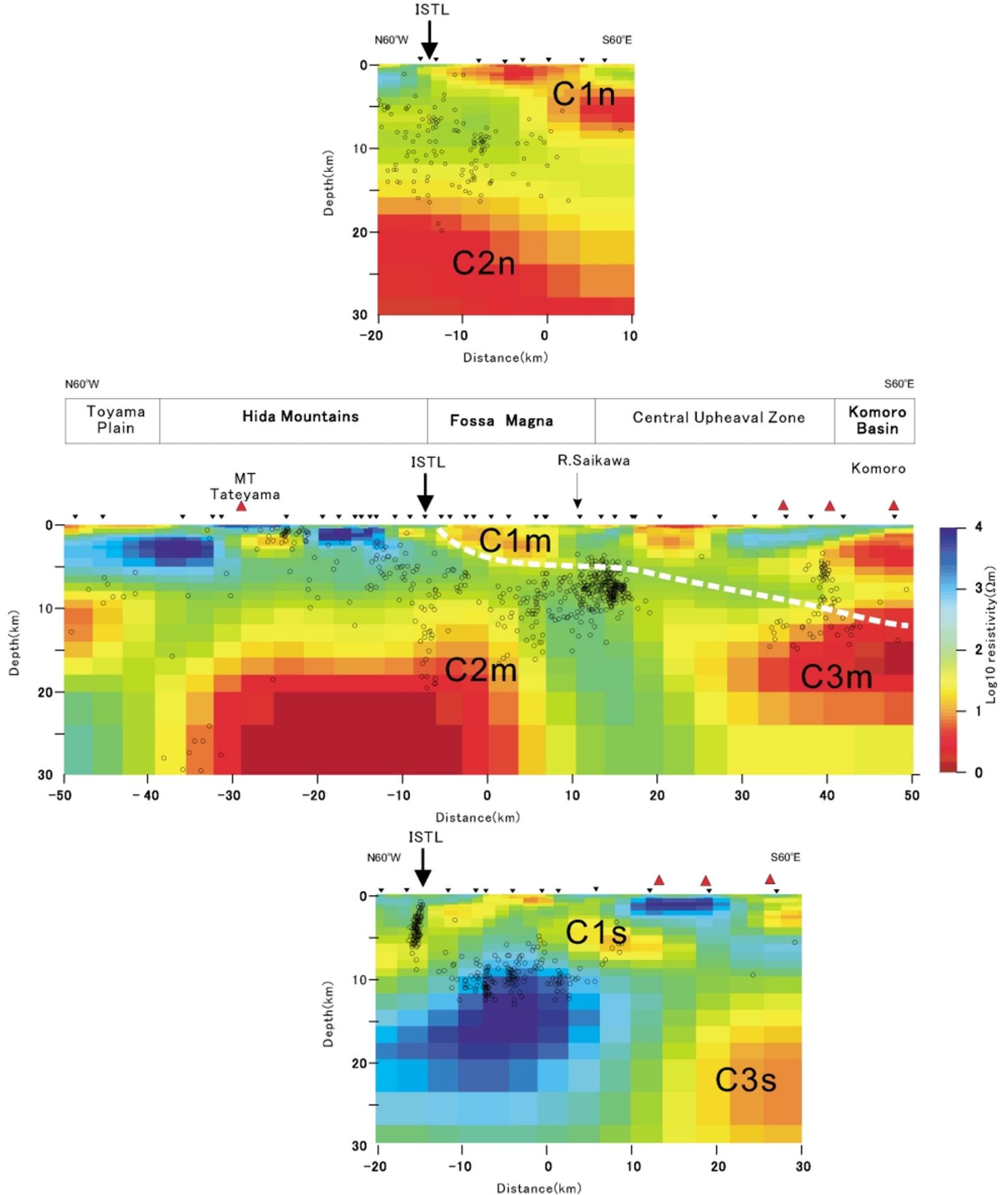

Fig. 3. Two-dimensional models for the north, the main and the south profiles. Major conductors are labeled. The triangles denote approximate locations of the nearby Quaternary volcanoes. The estimated fault geometry was plotted on the main profile with white line. The hypocenters were also projected using JMA dataset (from 1997 to 2002) along the profile with $10 \mathrm{~km}$ width.

main profile is already described by Ogawa et al. (2002). The model presented here for the main profile is from an inversion, which additionally included some near-by sites along the original profile. In this paper, we have two more profiles crossing the northern and southern edge of the fault segment so that we can study the along-strike variation of the resistivity structure.

\section{Modeling}

The dataset in the study area generally shows threedimensional features as described by Ogawa et al. (2002). According to the distributions of the two-dimensional strike directions from the tensor decompositions, the main profile did not have a single consistent strike direction for the whole profile, but rather sites within each geological di- 


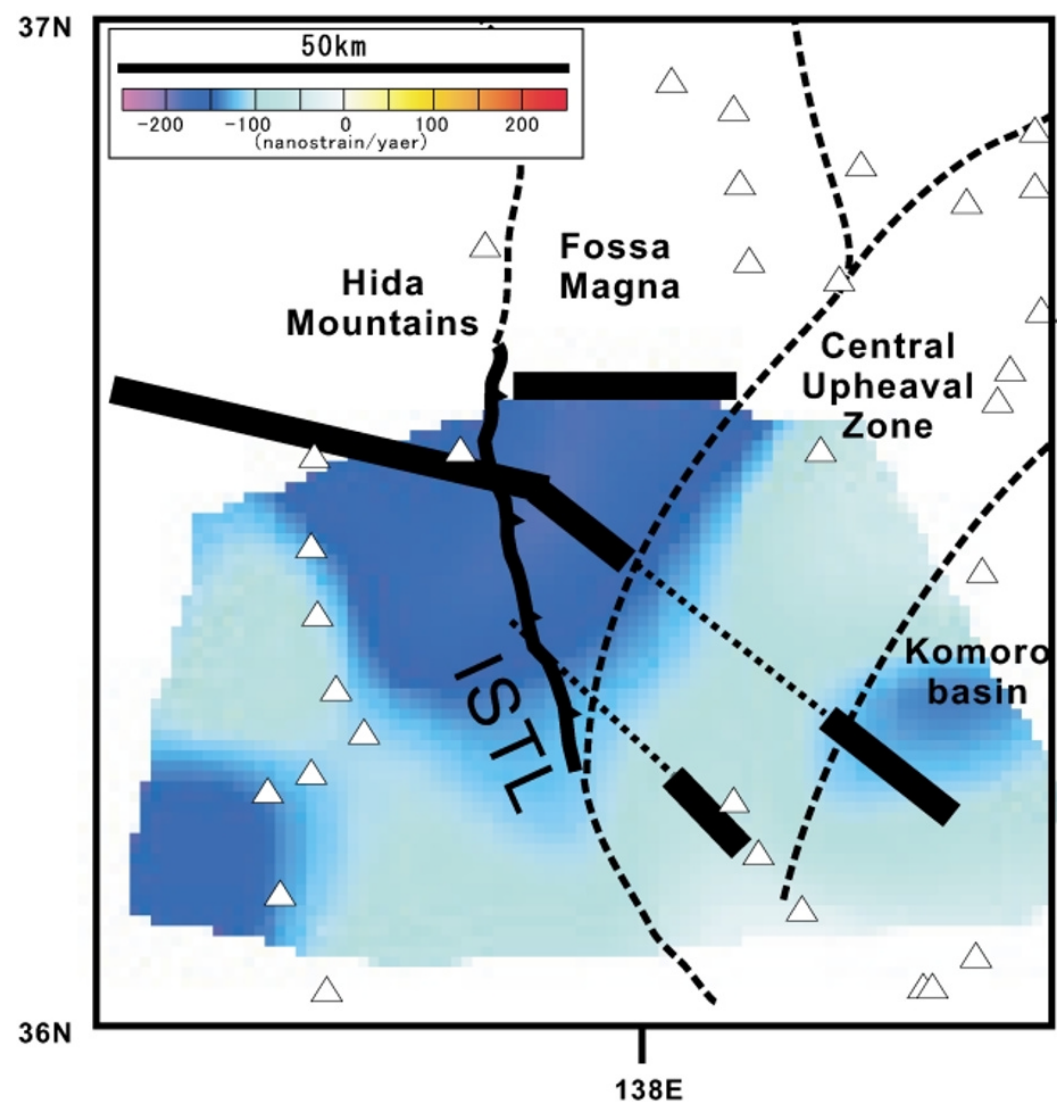

Fig. 4. Distribution of the mid-crustal conductors and the dilatation anomaly (Sagiya et al., 2004). MT profiles are shown by lines and the locations of the mid crustal conductors are shown by bold lines.

vision showed consistency in the strike directions. Thus, the full two-dimensional inversions using both TE and TM modes is not appropriate. By taking into account the robustness of the two-dimensional modeling in the three dimensional environment, we used TM mode data only for the subsequent analyses (Wannamaker et al., 1984; Ogawa, 2002). Since we are mostly interested in the structure under the Fossa Magna, we chose a coordinate system where impedance coordinates are parallel and perpendicular to the geologic strike $\left(\mathrm{N} 30^{\circ} \mathrm{E}\right)$. Then, we inverted TM mode data alone, where electric field runs along $\mathrm{N} 120^{\circ} \mathrm{E}$.

Figure 3 shows the three resistivity models after the two-dimensional inversions using the code of Ogawa and Uchida (1996). The rms values of the three profiles were 0.83 (north profile), 1.21 (main profile), and 1.34 (south profile), respectively where error floor for the apparent resistivity was set as $10 \%$ and that for the phase was set to the equivalent value.

All of the three models have the eastward thickening conductor east of ISTL in common (C1n, C1m, and C1s). These conductors imply the Miocene sediments and they thicken toward south-east consistent with the east-dipping fault geometry, inferred from seismic reflection survey (Sato et al., 2004) as shown by a white broken line in Fig. 3. Similar several kilometer thick sedimentary basin was also imaged by Ogawa et al. (2001) in NE Japan (KTY in Fig. 1), which is also under inversion tectonics.

On the other hand, the mid-crustal conductor at around $10 \mathrm{~km}$ depth distributes differently across the ISTL. In the north profile, the mid-crustal conductor below $10-15 \mathrm{~km}$ depths $(\mathrm{C} 2 \mathrm{n})$ exists over the entire profile. The main profile has a mid-crustal conductor to the east of ISTL (C2m) and it extends eastward under the Fossa magna. The location of the $\mathrm{C} 2 \mathrm{~m}$ conductor is consistent with the strong seismic reflectors at 7 and $12 \mathrm{~km}$ depth detected by seismic explosion experiment (Sato et al., 2004) and this coincidence supports the existence of fluids. In the south profile, however, the mid-conductor at ISTL is lost. The two-dimensionality does not hold for the mid-crustal conductors under ISTL.

The main and the south profiles have mid-crustal conductors below $10 \mathrm{~km}$ depth at the eastern ends (C3m and $\mathrm{C} 3 \mathrm{~s}$ ). These eastern sites are located close to the volcanoes (Figs. 2 and 3) and the mid-crustal conductors reflect distribution of fluids which were presumably supplied from the fluid release by re-crystallization of magmatic melt.

The main profile extends further westward over the Hida Mountains and detected deep crustal conductor under the north-south volcanic chains. The uplift of the Hida Mountains is believed to be a separate system from ISTL. The Hida Mountain is characterized by strong attenuation of seismic waves and by the low velocity (Matsubara et al., 2000). The low resistivity beneath the mountains below $10 \mathrm{~km}$ is consistent with the seismic tomography and implies fluids released from the dehydration under the mountain. From the MT modeling the mid-crustal conductor at the ISTL seems an eastern extension of the conductor under Hida Mountains. 


\section{Discussions}

The distribution of the hypocenters is projected on the three profiles (Fig. 3). We used JMA (Japan Meteorological Agency) dataset from 1997 to 2002 and projected the hypocenters along the profile with $10 \mathrm{~km}$ width. Most of the earthquakes distribute at the resistive upper crust, which is underlain by mid-crustal conductor. This means that the fluid distributes under the brittle-ductile boundary. Moreover it also means that the distribution of the fluid is not horizontally uniform, but localized. This inhomogeneity seems affecting the occurrence of the earthquake. In particular, the central upheaval area on the main profile does not have a mid-crustal conductor, and correspondingly the area has significantly small number of earthquakes. This suggests that the fluid is triggering the earthquakes.

Although the surface sedimentary units east of ISTL showed two-dimensionality along ISTL, the mid-crustal features vary along the strike of ISTL. The map (Fig. 4) shows the locations of the mid-crustal conductors (as thick lines) and the area of high dilatation inferred from GPS array (Sagiya et al., 2004). The area in general has negative dilatations. In particular, there are some sub-areas which show dilatation decrease of more than 100 nanostrain per year. In the north and main profiles, the existence of the mid-crust conductors is in harmony with the distinct negative dilatation. The south profile at the ISTL lacked the midcrustal conductor, and correspondingly the negative dilatation rate is not significant there. These correlations suggest that the crustal deformation is made easy by the distribution of fluids. The negative dilatation anomaly also reaches the eastern part of the main profile and may be relevant to the low resistivity in the mid-crust. However, the conductor of the southern profile at the eastern end does not have correlation to the dilatation.

Since the study area is a back arc side of the Pacific Plate subduction, the origin of the fluid comes from the hydrous minerals such as serpentine and chlorite on top of the subducting plate (Iwamori, 1998). They suffer dehydration at $150-200 \mathrm{~km}$ depth and released water is used for generation of melt to form a volcano in the back arc. When the melt re-crystallizes, the fluid is again released in the mid-crust. This will be source of the localized distribution of fluids in the mid-crust. In the case of New Zealand South Island (Wannamaker et al., 2002), which is a compressional regime without subduction, the fluid is supplied by the crustal thickening, i.e., crustal material is brought down to greater depth to cause dehydration. In this tectonic frame, the fluid distribution was horizontally continuous for more than $50 \mathrm{~km}$ long.

\section{Conclusions}

We imaged the resistivity structure of the crust at the northern part of the Itoigawa-Shizuoka tectonic line, where we have active fault segments. From the three magnetotelluric profilings, we found important features as below.

To a depth of $10 \mathrm{~km}$, the three profiles commonly showed the east-thickening Miocene sediments as conductors to the east of ISTL at the Fossa Magna. Thus the shallow geological structure keeps the two-dimensionality along the strike of ISTL.
We found the distribution of mid-crustal conductors, whose tops correlate with the brittle-ductile boundary. However the horizontal distribution of the conductor is localized. Thus we found the evidence for localized fluid distribution beneath the brittle-ductile boundary, which may host the slip region at the root of the fault system. The seismicity is high in the resistive upper crust, which is underlain by mid-crustal conductors. This suggests that fluid migration into less-fluid zone triggers earthquakes.

The mid-crustal conductors distribute differently along the strike of ISTL. The distribution of the mid-crustal conductors is well correlated with the distinct negative dilatation from GPS. This suggests that the existence of the fluid enables deformation of the crust.

Acknowledgments. This study was supported by the program "Comprehensive joint research on the modeling of slip process of earthquake source fault and plastic flow below the seismogenic region" of MEXT (Japanese Ministry of Education, Culture, Sports, Science and Technology). We thank discussions with Yoshihisa Iio, Takeshi Sagiya, Yoji Kobayashi, Hisao Ito, Hiroshi Sato, Yuzo Ishikawa, Koichiro Fujimoto, and Shinichi Takakura. We thank the constructive comments given by Phil Wannamaker and an anonymous reviewer. The magnetotelluric data acquisition was done by Sumiko Consultants Co. Ltd.

\section{References}

Cox, S., Fluid flow in mid- to deep crustal shear systems: Experimental constraints, observations on exhumed high fluid flux shear system, and implications for seismogenic processes, Earth Planets Space, 54, 11211125,2002

Fujimoto, K., T. Ohtani, N. Shigematsu, Y. Miyashita, T. Tomita, H. Tanaka, K. Omura, and Y. Kobayashi, Water-rock interaction observed in the brittle-plastic transition zone, Earth Planets Space, 54, 11271132, 2002.

Gratier, J-P, P. Favreau, F. Renard, and E. Pili, Fluid pressure evolution during the earthquake cycle controlled by fluid flow and pressure solution crack sealing, Earth Planets Space, 54, 11, 1139-1146, 2002.

Hobbs, B. E., H. Tanaka, and Y. Iio, Acceleration of slip motion in deep extensions of seismogenic faults in and below the seismogenic region, Earth Planets Space, 54, 1195-1205, 2002.

Honkura, Y., A. M. Işikara, N. Oshiman, A. Ito, B. Üçer, Ş. Bariş, M. Tunçer, M. Matsushima, R. Pektaş, C. Çelik, B. Tank, F. Takahashi, M. Nakanishi, R. Yoshimura, Y. Ikeda, and T. Komut, Preliminary results of multidisciplinary observations before, during and after the Kocaeli (Izmit) earthquake in the western part of the North Anatolian Fault Zone, Earth Planets Space, 52, 293-298, 2000.

Iio, Y. and Y. Kobayashi, A physical understanding of large intraplate earthquakes, Earth Planets Space, 54, 1001-1004, 2002.

Ikeda, Y. and N. Yonekura, Determination of late Quaternary rates of net slip on two major fault zones in Central Japan, Bull. Dept. Geogr. Univ. Tokyo, 18, 49-63, 1986.

Iwamori, H., Transportation of $\mathrm{H}_{2} \mathrm{O}$ and melting in subduction zones, Earth Planet. Sci. Lett., 160(1-2), 65-80, 1998.

Jones, A. G., Electrical conductivity of the lower continental crust, in Continental Lower Crust, edited by D. M. Fountain, R. J. Arculus, and R. W. Kay, Elsevier, Chapter 3, pp. 81-143, 1992.

Kasaya, T., N. Oshiman, N. Sumitomo, M. Uyeshima, Y. Iio, and D. Uehara, Resistivity structure around the hypocentral area of the 1984 Western Nagano Prefecture earthquake in central Japan, Earth Planets Space, 54, 107-118, 2002.

Kobayashi, Y., Initiation of plate subduction, Earth-Monthly, 5, 510-514, 1983 (in Japanese).

Lemonnier, C., G. Marquis, F. Perrier, J-P. Avouac, G. Chitrakar, B. Kafle, S. Sapkota, U. Gautam, G. Tiwari, and M. Bano, Electrical structure of the Himalaya of Central Nepal: High conductivity around the midcrustal ramp along the MHT, Geophys. Res. Lett., 26, 3261-3264, 1999.

Matsubara, M., N. Hirata, S. Sakai, and I. Kawasaki, A low velocity zone beneath the Hida Mountains derived from dense array observation and tomographic method, Earth Planets Space, 52, 143-154, 2000.

Miller, S. A., Inferring fault strength from earthquake rupture properties 
and the tectonic implications of high pore pressure faulting, Earth Planets Space, 54, 1173-1179, 2002.

Mitsuhata, Y., Y. Ogawa, M. Mishina, T. Kono, T. Yokokura and T. Uchida, Electromagnetic heterogeneity of the seismogenic region of 1962 M6.5 Northern Miyagi Earthquake, northeastern Japan, Geophysical Research Letters, 28, 4371-4374, 2001.

Nakamura, K., Possible nascent trench along the eastern Japan Sea as the convergent boundary between Eurasian and North American plates, Bull. Earthq. Res. Inst. Univ. Tokyo, 58, 711-722, 1983 (in Japanese).

Ogawa, Y., On two-dimensional modeling of magnetotelluric field data, Surveys in Geophysics, 23(2-3), 251-273, 2002.

Ogawa, Y. and Y. Honkura, An audiomagnetotelluric view of the Atera fault, J. Geomag. Geoelectr., 49, 1065-1071, 1997.

Ogawa, Y. and T. Uchida, A two-dimensional magnetotelluric inversion assuming Gaussian static shift, Geophys. J. Int., 126, 69-76, 1996.

Ogawa, Y., M. Mishina, T. Goto, H. Satoh, N. Oshiman, T. Kasaya, Y. Takahashi, T. Nisitani, S. Sakanaka, M. Uyeshima, Y. Takahashi, Y. Honkura, and M. Matsushima, Magnetotelluric imaging of fluids in intraplate earthquakes zones, NE Japan back arc, Geophysical Research Letters, 28, 3741-3744, 2001.

Ogawa, Y., S. Takakura, and Y. Honkura, Resistivity structure across Itoigawa-Shizuoka tectonic line and its implications for concentrated deformation, Earth Planets Space, 54, 1115-1120, 2002.

Okumura, K., K. Shimokawa, H. Yamazaki, and E. Tsukuda, Recent surface faulting along the middle section of Itoigawa-Shizuoka tectonic line-trenching survey of the Gofukuji fault near Matsumoto, central Japan, Zisin, 46, 425-438, 1994 (in Japanese)

Ritter, O., T. Ryberg, U. Weckmann, A. Hoffmann-Rothe, A. Abueladas, Z. Garfunkel, and DESERT-group, Geophysical images of the Dead Sea Transform in Jordan reveal an impermeable barrier for fluid flow, Geophysical Research Letters, 30, 14, 1741-1744, 10.1029/2003GL017541, 2003.

Sagiya, T., T. Nishimura, Y. Iio, and T. Tada, Crustal deformation around the northern and central Itoigawa-Shizuoka Tectonic Line, Earth Planets Space, 54, 1059-1063, 2002.

Sagiya, T., T. Nishimura, and Y. Iio, Heterogeneous crustal deformation along the central-northern Itoigawa-Shizuoka Tectonic Line Fault system, Central Japan, Earth Planets Space, 56, this issue, 1249-1254,
2004.

Sato, H. and Y. Ikeda, Crustal structure of NE Japan and extension tectonics, Earth Monthly, special volume, 27, 135-141, 1999. (in Japanese)

Sato, H., T. Iwasaki, Y. Ikeda, T. Takeda, N. Matsuta, T. Imai, E. Kurashimo, N. Hirata, S. Sakai, D. Elouai, T. Kawanaka, S. Kawasaki, S. Abe, T. Kozawa, T. Ikawa, Y. Arai, and N. Kato, Seismological and geological characterization of the crust in the southern part of northern Fossa Magna, central Japan, Earth Planets Space, 56, this issue, 12551261, 2004.

Sibson, R. H., F. Roberts, and K. H. Paulson, High-angle reverse faults, fluid-pressure cycling and mesothermal gold deposits, Geology, 16, 551-555, 1988.

Tanaka, A. and Y. Ishikawa, Temperature distribution and focal depth in the crust of the northeastern Japan, Earth Planets Space, 54, 1109-1113, 2002.

Tank, S. B., Y. Honkura, Y. Ogawa, N. Oshiman, M. K. Tunçer, M. Matsushima, C. Çelik, E. Tolak, and A. M. Işikara, Resistivity structure in the western part of the fault rupture zone associated with the 1999 İzmit earthquake and its seismogenic implication, Earth Planets Space, 55, 437-442, 2003.

Tank, S. B., Y. Honkura, Y. Ogawa, M. Matsushima, N. Oshiman, M. K. Tuncer, C. Celik, E. Tolak, and A. M. Isikara, Magnetotelluric imaging of the fault rupture area of the 1999 Izmit (Turkey) earthquake, Phys. Earth Planet Interior, 2004 (in press).

Unsworth, M., G. Egbert, and J. Booker, High-resolution electromagnetic imaging of the San Andreas fault in Central California, J. Geophys. Res., 104, 1131-1150, 1999.

Wannamaker, P. E., S. H. Ward, and G. W. Hohmann, Magnetotelluric responses of three-dimensional bodies in layered earth, Geophysics, 49 , 1517-1533, 1984.

Wannamaker, P. E., G. R. Jiracek, J. A. Stodt, T. G. Caldwell, V. M. Gonzalez, J. D. McKnight, and A. D. Porter, Fluid generation and pathways beneath an active compressional orogen, the New Zealand Southern Alps, inferred from magnetotelluric data, J. Geophys. Res., 10.1029/2001JB000186, 2002.

Y. Ogawa (e-mail: oga@ksvo.titech.ac.jp) and Y. Honkura 